\title{
Vegetarianism and growth in Urdu, Gujarati, and Punjabi children in Britain
}

\author{
R J RONA, S CHINN, S DUGGAL, AND A P DRIVER \\ From the Department of Community Medicine, United Medical and Dental Schools of Guy's and St Thomas's \\ Hospitals, St Thomas's Campus, London SE1 7EH
}

SUMMARY As part of a nutritional surveillance system of primary school children the relation between growth and vegetarianism in the Urdu, Gujarati, and Punjabi groups was explored. The aim of the analysis was to ascertain if vegetarian children from ethnic minorities are at a disadvantage in terms of nutritional status within their group of origin. Data for $80 \cdot 7 \%$ of 473 Urdu children, $86 \cdot 6 \%$ of 551 Gujarati children, and $84.4 \%$ of 1265 Punjabi children were available for the analysis. No significant differences in weight-for-height and triceps skinfold were found between vegetarians and non-vegetarians even after adjustment for potential confounding variables. Vegetarian girls tended to be shorter than non-vegetarian girls in all Asian groups, although this difference reached a statistically significant level $(p<0.01)$ only in the Urdu group. Although our findings should be interpreted with caution they indicate that health visitors and other health staff should be aware of the possible contribution of vegetarianism to the nutritional status of Asian girls.

In the UK there is little information relating the growth of children to vegetarianism. The issue may be of great revelance when dealing with ethnic groups of recent arrival in the country as they tend to occupy a disadvantageous socioeconomic position within the community. In the Indian subcontinent a large percentage of the Hindu community and a small percentage of the Sikh community exclude meat from the diet. These religions are common in the Gujarat and Indian Punjab from where sizeable numbers of people have migrated to the UK. Growth of Asian vegetarian children in this country can hypothetically be affected by the range of food permissible to them as well as the difficulties of having to adapt their diet to the conditions of the host country. These issues are worth exploring because a nutritional surveillance system has found primary school children whose parents speak Gujarati to be shorter than children from any other group from the Indian subcontinent. ${ }^{1}$ By using an answer to a question about child vegetarianism we have explored the relation between vegetarian status and growth in terms of height, weight-for-height, and triceps skinfold of children whose parents speak Urdu, Gujarati or Punjabi.

\section{Materials and methods}

The National Study of Health and Growth (NSHG), a nutritional surveillance system of primary school children, is following two samples, one obtained from a stratified random sampling and another from electoral wards in inner city areas with high proportions of persons born in the New Commonwealth countries of America and Asia. ${ }^{1}$ In 1983, this latter sample was surveyed for the first time. Measurement techniques for height, weight, and triceps skinfold recommended by Tanner and collaborators were followed. ${ }^{23}$ Parents completed a self-adminstered questionnaire on family social circumstances and child's well-being. The questionnaire included the question, "Is this child vegetarian?" and, if the answer was "yes", the questionnaire enquired further, "Does your child eat eggs, cheese, milk, and other dairy products?"

Ethnic origin was divided into groups: Caucasian, Afro-Caribbean, Urdu, Gujarati, Punjabi, "other Asian," and "others" based on fieldworkers' subjective assessment and the language spoken at home. ${ }^{1}$

The dependent variables analysed were: height, weight-for-height, and triceps skinfold. The results are presented in standard deviation scores (SDS), ie, the SDS for height is the difference between a child's height and the mean height of a group of the same age and sex divided by the standard deviation for that group. ${ }^{4}$ As the distributions of weight and triceps skinfold are skewed, to obtain the appropriate SDS for a child the measurements were logarithmically 
transformed to give an approximate Gaussian distribution in each age group. ${ }^{5}$ One SDS of height is equivalent to about $5 \mathrm{~cm}$ at 5 years of age and $7 \mathrm{~cm}$ at 11 years. The SDS presented are based on the distributions for each measurement taken in the 1982 survey which was carried out on the stratified random sample. ${ }^{1}$ These children were almost entirely Caucasian.

Multiple regression analysis was used to assess the association between each dependent variable and each independent variable after adjustment for the remaining factors of two models, $A$ and $B .^{1}$ These two models had a set of common factors: father's and mother's height, child's birthweight, household overcrowding, and number of siblings. Parents' weight was included for the analysis of weight-for-height and triceps skinfold. They differed in so far as model A included type of school and mother's level of education, and model B included father's social class and employment status and mother's hours of work outside the home. Child's vegetarian status was added to both models. The two models were designed to

Table 1 Vegetarian status according to ethnic group

\begin{tabular}{|c|c|c|c|c|}
\hline \multirow[b]{2}{*}{ Ethnic group } & \multicolumn{2}{|c|}{ Vegetarian } & \multirow{2}{*}{$\begin{array}{l}\text { Non-vegetarian } \\
\%\end{array}$} & \multirow{2}{*}{$\begin{array}{l}\text { Not known } \\
\%\end{array}$} \\
\hline & No. & $\%$ & & \\
\hline Caucasian & 2794 & 1.8 & $81 \cdot 7$ & $16 \cdot 5$ \\
\hline Afro-Caribbean & 952 & $1 \cdot 3$ & $68 \cdot 0$ & 30.8 \\
\hline Urdu & 473 & $11 \cdot 8$ & 68.9 & $19 \cdot 2$ \\
\hline Gujarati & 551 & 31.4 & $56 \cdot 8$ & 11.8 \\
\hline Punjabi & 1265 & 11.4 & $74 \cdot 2$ & $14 \cdot 5$ \\
\hline Other Asian & 286 & $11 \cdot 2$ & $74 \cdot 5$ & $14 \cdot 3$ \\
\hline Others & 544 & 4.4 & $67 \cdot 3$ & $28 \cdot 3$ \\
\hline Not known & 238 & $2 \cdot 9$ & $26 \cdot 1$ & $71 \cdot 0$ \\
\hline Total & 7103 & & & \\
\hline
\end{tabular}

minimise the overlap of variables that served as proxy measures for very similar social conditions.

\section{Results}

Table 1 shows the percentage of vegetarians according to ethnic origin. The percentage of vegetarians was very low in the Caucasian and Afro-Caribbean children. In the Asian groups, as expected, the highest percentage of vegetarians was seen in children from Gujarati speaking families (36\% after adjustment for not knowns) and the other groups all have around $11 \%$. The rest of the analysis concentrates on the groups of children of Urdu, Gujarati, and Punjabi origin. We decided to exclude the other groups from further analysis because the non-Asian groups have a $\vec{\circ}$ very low percentage of vegetarians, and the "other Asians" group was too heterogeneous to allow useful analysis.

Vegetarians and non-vegetarians had very similar distributions in the Gujarati, Punjabi, and Urdu groups for father's social class, father's current employment status, number of children in the family and free school meals. There were more mothers wit: no schooling or elementary education only in the vegetarian group from all three ethnic groups.

Almost all vegetarian children consumed milk an\& dairy products and most Punjabi and Urd vegetarians ate eggs and cheese. Approximately $25 \%$ of vegetarian Gujarati did not eat eggs and cheese.

Table 2 gives the unadjusted mean SDS for heigh weight-for-height, and triceps skinfold for the Urdu, Gujarati, and Punjabi groups by vegetarian status and sex. As the SDS are based on the quasi-representative sample most of the means are negative. In the Gujarati and Punjabi groups we could find no significant

Table 2 Mean SDS of height, weight-for-height, and triceps skinfold (1982 definitions) by sex and vegetarian status in Urdu, Gujarati, and Punjabi children

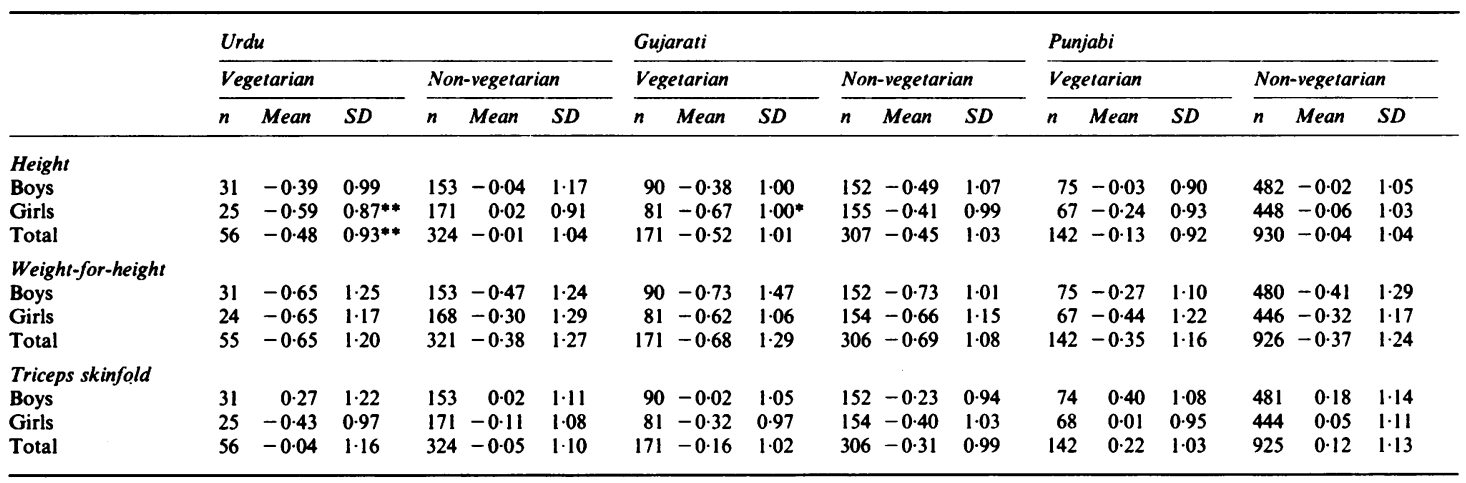

* $\mathrm{p}<0 \cdot 1$

$* * \mathrm{p}<0.01$ 
difference in any of the indices of nutritional status in boys, girls, and the total. Within the Gujarati girls the vegetarians were shorter than non-vegetarians, and the difference approached significance level $(p<0 \cdot 1)$. None of the differences was significant after adjustment for the other independent variables in model A or model B. In Urdu girls, and in the total Urdu group vegetarians were significantly shorter than non-vegetarians $(p<0.01)$. These differences persisted after adjustment in the multiple regression analysis.

\section{Discussion}

In this paper we have restricted the study of vegetarianism and growth to groups of recent emigration to the UK who have a long tradition of meat exclusion from their diet. These groups need to be distingushed from vegetarians from other ethnic groups, mainly Caucasians, who have converted to vegetarianism only recently for health or ideological reasons. The groups of more recent conversion tend to belong to a specific social group, and it would be more appropriate to study their growth in comparison with the more representative sample of the NSHG obtained from a stratified random sampling. Vegetarians in the Afro-Caribbean community would be an interesting group to study because of their recent drive towards a stricter form of vegetarianism. Only 12 children were vegetarians in the the Afro-Caribbean group studied and the vegetarianism of these children may vary in strictness.

Concern about the vegetarian status of Asian people in Britain has been expressed ${ }^{6}$ and is backed by research on the diet of people, originally from the Indian subcontinent, coming to the UK from East Africa. Their food intake has been shown to be below DHSS reccommendations in terms of energy, protein, iron, and vitamin $\mathrm{D} .{ }^{7}$ Most severe deficiencies are seen among Hindu families. However, as this survey was carried out in 1972, the relevance of the results in the eighties is uncertain. A further worrying discovery is that Gujarati children, the group with the highest rate of vegetarianism, also had the shortest stature among the ethnic groups in the surveillance system. ${ }^{1}$

In the current analysis there was no significant association between indices of nutritional status and vegetarianism within the Gujarati and Punjabi groups. However, in Urdu girls, vegetarians were significantly shorter than non-vegetarians. The same tendency, albeit not statistically significant, was found in Urdu boys and Gujarati and Punjabi girls. A possible explanation of our findings is that the question on vegetarianism was poorly understood by the parents in the Asian community with more limited education. There are two elements in favour of this explanation: firstly, the relatively high percentage of vegetarians within the Urdu speaking group, which we expected would be mainly Muslim and meat eaters, and, secondly, that a lower education level was attained by mothers in the vegetarian groups than in the nonvegetarian groups. However, in the 1985 survey the question on vegetarianism was made more explicit to reduce misinterpretations, but this change did not reduce the number of vegetarians in any of the three ethnic Asian groups. Moreover, in the multiple regression analyses, adjustment for mother's education did not modify the results presented in table 2.

The high percentage of vegetarians in the Urdu group was not concentrated in a particular study area. It is possible that within the Urdu speaking group in Britain there is a subset who are of the Hindu religion, and this would explain the $11 \%$ of vegetarians in the Urdu sample.

In a previous draft of this paper we excluded the Urdu group because we were inclined to believe that there was some error in the vegetarian data in that group. This approach would have conveyed no association between vegetarianism and nutritional status. By including the Urdu group differences in height by sex between vegetarians and nonvegetarians are enhanced. It is possible that food distribution within the vegetarian families on average favours boys or that other environmental factors related to growth are more favourable to boys than to girls. An alternative explanation would be genetic heterogeneity within the three Asian groups. Eveleth ${ }^{8}$ reported large differences in sex dimorphism of adult height, and for some groups a genetic explanation was given. In the case analysed, however, it is highly unlikely that the sex dimorphism is due to genes and restricted to the three vegetarian subsets of each language group.

In conclusion we would recommend that nutritional status in vegetarian girls should be carefully monitored in groups and individuals of the Asian community.

We thank Professor W W Holland for his support and encouragement. We acknowledge the assistance of all our colleagues, Department of Health and Social Security and the Scottish Home and Health Department.

\section{References}

${ }^{1}$ Rona RJ, Chinn S. National Study of Health and Growth: Social and biological factors associated with height of children from ethnic groups living in England. Ann Hum Biol 1986; 13: 453-71. 
2 Tanner JM, Whitehouse RH. Standards for subcutaneous fat in British children. Percentiles for thickness of skinfolds over triceps and below scapula. Br Med J 1962; i: $446-50$.

3 Tanner JM, Whitehouse RH, Takaishi M. Standards from birth to maturity for height, weight, height velocity and weight velocity: British children, 1965. Part I and II. Arch Dis Child 1966; 41: 454-71, 613-35.

${ }^{4}$ Rona RJ, Swan AV, Altman DG. Social factors and height of primary schoolchildren in England and Scotland. $J$ Epidemiol Community Health 1978; 32: 147-54.
${ }^{5}$ Rona RJ, Chinn S. National Study of Health and Growth Social and biological factors associated with weight-forheight and triceps skinfold of children from ethnic groups in England. Ann Hum Biol (in press).

${ }^{6}$ Henley A. Asian patients in hospital and at home. Bath Pitman Press, 1979.

${ }^{7}$ Community Relations Commission. Refuge or home? A policy statement on the resettlement of refugees. London, 1976.

${ }^{8}$ Eveleth PB. Differences between ethnic groups in sex dimorphism of adult height. Ann Hum Biol 1975; 2: 35-9.

\section{World Conference on Health Education}

A call for Abstracts is announced for the XIII World Conference on Health Education which will be held 28 August to 2 September 1988 in Houston, Texas, USA. The deadline for international abstract submissions is 30 October 1987. Presenters are invited to submit abstracts that address the conference theme, "Participation for All in Health" or its four subthemes: Involving people and community; Supporting community access; Involving the total health system; and, Gaining intersectoral support. Papers should describe the populations being reached, the problems being addressed, and the process involved. To obtain abstract forms and information, telephone the conference headquarters at (713) 792-8540 or write to the United States Host Committee, PO Box 20186, W-902, RAS Building, Houston, Texas 77225, USA. 